\title{
Improved Callus Quality and Prolonged Regenerability in Model and Recalcitrant Barley (Hordeum vulgare L.) Cultivars
}

\author{
Wen JIANG, Myeong-Je CHO and Peggy G. LEMAUX* \\ Department of Plant and Microbial Biology, University of California, Berkeley, CA 94720, USA \\ Received 16 May 1997; accepted 20 January 1998
}

\begin{abstract}
In vitro performance of immature embryo-derived callus of two barley cultivars, the amenable cultivar, Golden Promise (GP) and the recalcitrant commercial cultivar, Galena (GL), was tested on fourteen media containing combinations of two auxins, dicamba and 2,4-dichlorophenoxyacetic acid (2,4-D) and two cytokinins, 6-benzylaminopurine (BAP) and zeatin. Generalizations for both cultivars include the fact that callus-induction frequencies on dicamba and 2,4-D alone and dicamba plus zeatin were nearly $100 \%$. Qualitative appearance for both cultivars was nearly identical on comparable media but markedly better on BAP-containing media. The addition of zeatin with either auxin supported vigorous growth due to the proliferation of nonregenerable callus; the presence of BAP produced higher quality callus although it inhibited the relative growth rate. GP calli grown on $2,4-\mathrm{D}$ plus $0.01 \mathrm{mg} / \mathrm{L}$ BAP regenerated the largest number of green shoots at most time points relative to other media, while GL tissue on 2,4-D plus $0.1 \mathrm{mg} / \mathrm{L}$ BAP yielded the most green shoots at all but one time point. Over time regenerability was lost more rapidly in GL than GP except on 2,4-D plus BAP media; GL had a higher propensity toward albinism than GP. In both cultivars, the use of 2,4-D and BAP yielded tissue that proliferated for prolonged periods in a regenerable state.
\end{abstract}

\section{Introduction}

Barley (Hordeum vulgare L.) is one of the most important cereal crops in the world, following closely in total production, wheat, rice and maize. Therefore, the ability to genetically engineer this crop to improve its performance and pest-resistance qualities or to enhance its alternative uses is of great importance. The practical utility of stable transformation technologies is largely dependent on having efficient methods to generate large numbers of fertile green plants from in vitro-cultured materials of commercially important germplasm. A successful, high-frequency barley transformation procedure was reported [1]; however, the protocol was developed for the amenable variety, Golden Promise (GP) and has been limited in its applicability to commercially important cultivars. This limitation is due in part to the gradual loss over time of embryogenic capacity and regenerability of callus tissue and to an increase in albino plants during the prolonged culturing periods needed for selection of transformed tissue.

Phytohormones are critical to establishing optimal culture conditions since they play a pivotal role in producing relatively undifferentiated callus tissue

* To whom correspondence should be addressed. from differentiated tissues like the embryo. Both auxins and cytokinins are required for cell division [2] and, during in vitro culture, the balance between the two hormones determines what developmental tissue types are formed from the cell divisions [3]. The particular types of auxins and cytokinins chosen also affect the quality, growth and regenerative potential of callus. For example, Hagio et al. [4] used 0. $1 \mathrm{mg} / \mathrm{L}$ of the cytokinin, 6 -benzylaminopurine (BAP) in combination with $2.0 \mathrm{mg} / \mathrm{L}$ of the auxin 2,4-dichlorophenoxyacetic acid $(2,4-\mathrm{D})$ for callus induction and maintenance of callus from the barley cultivars GP, Haruna Nijo, Dissa and New Golden. In these studies, albino plants were not observed after hygromycin selection and this might have been attributable to the use of BAP. BAP has been observed previously to prevent senescence in cytokinin-treated leaf samples of intact bean plants [5]; however, in the Hagio et al. study [4], this possibility was not investigated. Data from another study showed that at low concentrations the cytokinins, zeatin and zeatin riboside, in combination with the auxin, indole-3acetic acid (IAA) increased the regeneration frequency of $H$. vulgare varieties GP and Dissa, while other cytokinins, like BAP, kinetin and 6- (3-methyl2 butenyl 1-amino) purine (2iP), induced browning of callus [6]. In another study, looking at plant regeneration from $H$. spontaneum and $H$. bulbosum im- 
mature embryo (IE)-derived calli, it was concluded that medium containing IAA and zeatin improved regeneration frequencies [7]. Based on the results from these studies, it seemed likely that the appropriate use of phytohormones could prolong regenerability and reduce albinism during in vitro culture .

The experiments reported here were designed to optimize in vitro culture conditions for an amenable cultivar used frequently for transformation, GP $[1,4$, $8,9]$, and another commercial cultivar, Galena (GL), recalcitrant to published transformation methods. This optimization was accomplished by altering the combinations and levels of auxins and cytokinins during induction and maintenance of callus from IEs and observing the effects of these changes on callusinduction frequency, growth rate, quality, long-term regenerability and albinism of the tissue.

\section{Materials and Methods}

\section{1 Donor plants}

IEs from GP and GL were used in these experiments. The donor plants were grown in soil under controlled conditions in growth chambers as described $[1,8]$.

\section{2 Media}

Fourteen different media were designed for callus induction and maintenance (CIM). Two auxins (dicamba and 2,4-D) and two cytokinins (BAP and zeatin) were used at different concentrations and in different combinations in the callus-induction medium (CIM) (Table 1, left-hand columns). The medium was MS [10] supplemented with $30 \mathrm{~g} / \mathrm{L}$ maltose, 1.0 $\mathrm{mg} / \mathrm{L}$ thiamine- $\mathrm{HCl}, 0.25 \mathrm{~g} / \mathrm{L}$ myo-inositol, $1.0 \mathrm{~g} / \mathrm{L}$ casein hydrolysate and $0.69 \mathrm{~g} / \mathrm{L}$ proline, solidified with $3.5 \mathrm{~g} / \mathrm{L}$ Phytagel (Sigma, St. Louis, MO). The regeneration medium was FHG [11], supplemented with $1 \mathrm{mg} / \mathrm{L}$ BAP and solidified with $3.0 \mathrm{~g} / \mathrm{L}$ of Phytagel.

\section{3 Callus-induction frequency, growth rate and morphological scoring}

Spikes at 14 to $20 \mathrm{~d}$ after pollination were surfacesterilized in $20 \%(\mathrm{v} / \mathrm{v})$ bleach $(5.25 \%$ sodium hypochlorite) for $7 \mathrm{~min}$ and washed $5 \mathrm{~min}$ with sterile water 3 times. IEs about 1.5 to $2.5 \mathrm{~mm}$ in size were bisected longitudinally and placed on the fourteen different CIM. Callus-induction frequency was measured by counting numbers of half-IEs undergoing callus induction under a light microscope 2 to 3 weeks after initial culturing. Each treatment had 3 replicates.

For determining growth rates ten half-IEs were placed scutellum-side down on each medium and cultured in the dark at $24 \pm 1^{\circ} \mathrm{C}$; each treatment had 3 replicates. From the 2 nd transfer 10 callus pieces ( 3

Table 1. Callus-induction frequency and qualitative appearance of Golden Promise (GP) and Galena (GL).

\begin{tabular}{|c|c|c|c|c|c|c|c|}
\hline \multirow{2}{*}{$\begin{array}{l}\text { Auxin } \\
\text { Conc. } \\
\text { (mg/L) }\end{array}$} & \multirow{2}{*}{$\begin{array}{l}\text { Cytokinin } \\
\text { Conc. } \\
\text { (mg/L) }\end{array}$} & \multicolumn{2}{|c|}{$\begin{array}{l}\text { Callus Induction } \\
\text { Frequency }(\%)^{* 1}\end{array}$} & \multicolumn{2}{|c|}{$\begin{array}{c}\text { Callus } \\
\text { Morphology*2 }\end{array}$} & \multicolumn{2}{|c|}{$\begin{array}{l}\text { Callus } \\
\text { Color*3 }\end{array}$} \\
\hline & & GP & GL & GP & $\mathrm{GL}$ & GP & $\mathrm{GL}$ \\
\hline Dicamba & BAP & & & & & & \\
\hline (1) 2.5 & 0 & $100.0 \pm 0$ & $100.0 \pm 0$ & $+++(+)$ & + & ++ & + \\
\hline (2) 2.5 & 0.01 & $96.3 \pm 5.2$ & $92.6 \pm 5.2$ & +++ & $+(+)$ & ++ & ++ \\
\hline (3) 2.5 & 0.1 & $88.9 \pm 0$ & $71.3 \pm 12.4$ & +++ & ++ & ++ & ++ \\
\hline (4) 2.5 & 0.5 & $92.6 \pm 5.2$ & $54.2 \pm 5.9$ & +++ & +++ & +++ & +++ \\
\hline $2,4-\mathrm{D}$ & BAP & & & & & & \\
\hline (5) 2.5 & 0 & $92.6 \pm 5.2$ & $100.0 \pm 0$ & +++ & $+(+)$ & ++ & ++ \\
\hline (6) 2.5 & 0.01 & $100.0 \pm 0$ & $96.3 \pm 5.2$ & $+++(+)$ & ++ & +++ & +++ \\
\hline (7) 2.5 & 0.1 & $84.3 \pm 6.6$ & $84.3 \pm 6.6$ & ++++ & +++ & ++++ & $+++(+)$ \\
\hline (8) 2.5 & 0.5 & $92.6 \pm 5.2$ & $75.0 \pm 0$ & ++++ & +++ & ++++ & ++++ \\
\hline Dicamba & Zeatin & & & & & & \\
\hline (9) 2.5 & 0.01 & $100.0 \pm 0$ & $96.3 \pm 5.2$ & ++ & + & + & + \\
\hline (10) 2.5 & 0.1 & $100.0 \pm 0$ & $100.0 \pm 0$ & +++ & ++ & + & + \\
\hline (11) 2.5 & 0.5 & $100.0 \pm 0$ & $100.0 \pm 0$ & ++ & + & + & + \\
\hline $2,4-\mathrm{D}$ & Zeatin & & & & & & \\
\hline (12) 2.5 & 0.01 & $79.6 \pm 6.6$ & $100.0 \pm 0$ & ++ & + & + & + \\
\hline (13) 2.5 & 0.1 & $88.0 \pm 10.2$ & $88.9 \pm 0$ & $+(+)$ & $+(+)$ & + & + \\
\hline (14) 2.5 & 0.5 & $100.0 \pm 0$ & $100.0 \pm 0$ & ++ & + & + & + \\
\hline
\end{tabular}

*1 Values represent means \pm standard deviation of three replicates for each treatment.

*2 Morphology includes the degree of compactness and shine, from ++++ , being the most compact and shiny callus to + , being the least compact and shiny callus.

$* 3$ Color is from slightly brown $(++++)$ to white $(+)$. 
to $4 \mathrm{~mm}$ in size) per Petri dish were maintained on each medium. Every 2 to 3 weeks callus pieces were weighed and the growth rate determined by weighing the plate containing the callus pieces before transfer $\left(W_{1}\right)$ and after transfer of all tissue $\left(W_{2}\right)$. The relative growth rate of the callus was calculated as the change in weight $(W)$ of the callus $\left(W=W_{1}-W_{2}\right)$ divided by the weight of tissues originally plated $\left(\mathrm{W}_{0}\right)$ and the number of culture days ( $\mathrm{g} / \mathrm{g}$ fresh weight/ day). From the 3rd transfer, three of the highest quality pieces from each embryo, rather than all calli, were transferred to fresh medium; all untransferred calli were removed to obtain $W_{2}$.

Qualitative appearance of the callus (morphology and color) was assessed microscopically 2 to 3 weeks after initial callus induction. For morphology, a score of ++++ was given to shiny, compact, nodular callus (the highest quality); a score of + being given to soft, friable callus (the lowest quality). Color was judged from slightly brown-colored callus $(++++)$ to white $(+)$.

\section{4 Regeneration}

To test regeneration ten pieces ( 3 to $4 \mathrm{~mm}$ ) of the highest quality callus from each treatment were transferred to $\mathrm{FHG}$ regeneration medium in three replicates at varying times during the culture period. Dishes were placed under fluorescent lights (45 to 55 $\mu \mathrm{Em}^{-2} \cdot \mathrm{s}^{-1}, 16 \mathrm{~h}$ light/8h dark). Numbers of shoots per callus piece were counted about 22-25 days after transfer.

\section{Results}

\section{1 Induction frequency, relative growth rate and qualitative appearance of callus}

To examine the effects of different concentrations/ types of auxins and cytokinins on induction frequency, quality and subsequent growth rate of callus, fourteen different media were tested (Table 1). On most media, callus-induction frequencies were not significantly different for the two cultivars; dicamba and 2,4-D alone and dicamba with zeatin at all concentrations resulted in nearly $100 \%$ induction frequencies for both cultivars. GP had a higher callus-induction frequency than GL on three of the fourteen media tested, dicamba plus the two highest concentrations of $\operatorname{BAP}(0.1,0.5 \mathrm{mg} / \mathrm{L})$ and 2,4-D plus the highest BAP concentration. Only one medium $(2,4-\mathrm{D}+0.01 \mathrm{mg} / \mathrm{L}$ zeatin) led to a higher frequency for GL.

In general, callus morphology of GP was better than that of GL on nearly all media tested (Table 1; Fig. 1). However, certain trends in the qualitative appearance were seen for both cultivars. First, the use of BAP with either 2,4-D or dicamba produced better morphological appearance than use of either auxin with zeatin. Second, callus color was dramatically affected by the type of cytokinin. While the use
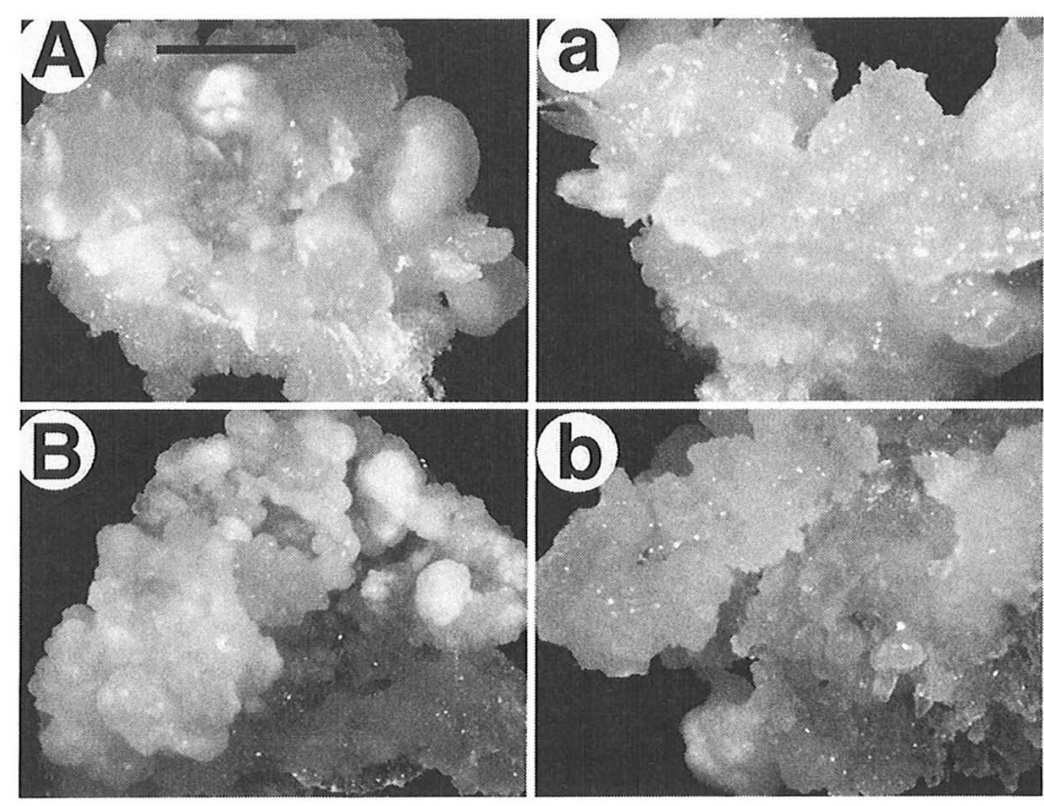

Fig. 1 Callus morphology of two barley cultivars, Golden Promise $(\mathrm{A}-\mathrm{B})$ and Galena $(\mathrm{a}-\mathrm{b})$, on $\mathrm{BAP}$-containing medium. The hormone combinations of the callus-induction media were as follows: A and a, $2.5 \mathrm{mg} / \mathrm{L}$ of $2,4-\mathrm{D}$ alone; $\mathrm{B}$ and $\mathrm{b}$, $2.5 \mathrm{mg} / \mathrm{L}$ of $2,4-\mathrm{D}$ plus $0.1 \mathrm{mg} / \mathrm{L}$ of BAP. Photographs were taken 2 weeks after initial callus induction. Bar in $\mathrm{A}=0.5$ $\mathrm{cm}$ 

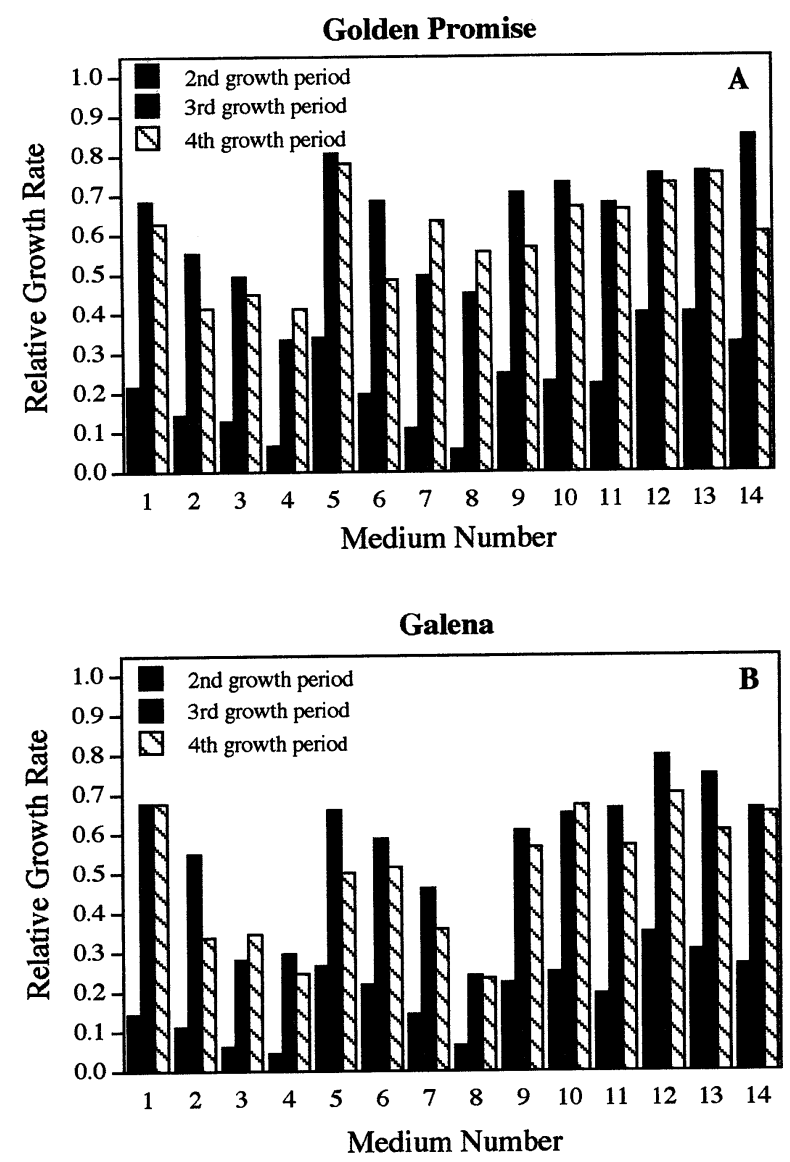

Fig. 2 Relative growth rate (g/g fresh weight/day) of callus of two barley cultivars, Golden Promise (A) and Galena (B), grown on fourteen different callus-induction media. Hormone combinations of the different media are noted in Table 1.

of zeatin at all levels with either auxin led to the formation of poor quality callus, increasing levels of BAP with either auxin led to larger amounts of slightly brown-colored callus. Third, medium containing higher concentrations of $\operatorname{BAP}(0.1 / 0.5 \mathrm{mg} / \mathrm{L})$ with 2 , 4-D appeared to support the production of higher quality callus (morphology) than did the lower concentration of BAP $(0.01 \mathrm{mg} / \mathrm{L})$.

For both cultivars, the relative growth rate increased rapidly after the first transfer, reaching its maximum during the third transfer (Fig. 2); the growth rates dropped significantly after the fourth transfer (data not shown). In the first growth period, determination of growth rate was complicated by the rapid increase in fresh weight of the embryo due to imbibition. In general, for both cultivars, the use of BAP slowed growth rates compared to those in the absence of this cytokinin or in the presence of zeatin. GP appeared to grow faster than GL on media containing dicamba plus BAP and 2,4-D +/- BAP. Both cultivars grew faster on 2,4-D-containing medium with BAP than dicamba in combination with the same concentration of BAP except at $0.5 \mathrm{mg} / \mathrm{L}$ of BAP for GP. There appeared to be no difference between cultivars in growth rate on medium containing 2,4-D or dicamba in combination with zeatin. The use of low concentrations of zeatin $(0.01$ or 0.1 $\mathrm{mg} / \mathrm{L}$ ) in combination with dicamba or 2,4-D did not appear to inhibit the callus growth rate of GP relative to growth on dicamba or 2,4-D alone. The combination of low concentrations of zeatin with 2,4-D seemed to increase callus growth rate of GL up to the fourth growth period relative to $2,4-\mathrm{D}$ alone (Fig. 2).

\section{2 Plant regeneration}

Calli of GP and GL were tested for regeneration ability. At most points on most media, GP produced a higher number of green calli (NC) and green shoots (NS) per 10 initial callus pieces than did GL (Table 2). In addition GL calli appeared to lose regenerability at a faster rate than GP except for that on medium containing BAP in combination with 2,4-D. Callis of GL responded more favorably than GP on all levels of BAP. Through the fifth transfer, the trends for NC and NS in all treatments for GP appeared comparable, although the use of 2,4-D plus 0.01 and 0 . $5 \mathrm{mg} / \mathrm{L}$ BAP might have led to higher $\mathrm{NC}$ at the fifth transfer. In most cases NC and NS for GP decreased dramatically after either the fifth or seventh transfers. Few media supported long-term regeneration of plants for GP (ninth transfer), only dicamba and 2,4D plus $0.1 \mathrm{mg} / \mathrm{L}$ BAP and 2,4-D plus $0.5 \mathrm{mg} / \mathrm{L}$ zeatin. For GL, the ability to generate green shoots was lost more rapidly than GP on medium containing either dicamba or 2,4-D with zeatin or dicamba in combination with BAP. The only media supporting longterm (7th transfer and beyond) maintenance of greening and regeneration of plants for GL was 2,4-D plus BAP at all levels; $0.1 \mathrm{mg} / \mathrm{L}$ appeared optimal at the latest time point. This medium also supported a faster callus growth rate than dicamba plus a comparable level of BAP (Fig. 2). For both cultivars, medium containing BAP plus 2,4-D, and to a lesser extent dicamba, supported the development of multiple shoots from shiny, compact callus tissues, compared to few or no shoots on a medium containing 2,4-D alone (Fig. 3; Table 2).

\section{Discussion}

Frequencies of induction, quality and regenerability of callus in barley are influenced by a variety of factors, e.g. medium composition [6, 12-15], levels and types of phytohormones $[6,16-18]$, length of time in culture [18-20], embryo size $[12,17,21]$ and cultivar $[6,13-15,21,22]$. The present study confirms and expands these observations to the trans- 
Table 2. Regeneration from calli of Golden Promise (GP) and Galena (GL) grown on fourteen different media.

\begin{tabular}{|c|c|c|c|c|c|c|c|c|c|c|c|c|}
\hline \multirow{2}{*}{ Genotype } & \multirow{2}{*}{$\begin{array}{l}\text { Auxin Conc. } \\
(\mathrm{mg} / \mathrm{L})\end{array}$} & \multirow{2}{*}{$\begin{array}{l}\text { Cytokinin } \\
\text { Conc. } \\
(\mathrm{mg} / \mathrm{L})\end{array}$} & \multicolumn{2}{|c|}{ 3rd transfer } & \multicolumn{2}{|c|}{ 4th transfer } & \multicolumn{2}{|c|}{ 5th transfer } & \multicolumn{2}{|c|}{ 7th transfer } & \multicolumn{2}{|c|}{ 9th transfer } \\
\hline & & & $\mathrm{NC}^{* 1}$ & $\mathrm{NS}^{* 2}$ & $\mathrm{NC}$ & NS & $\mathrm{NC}$ & NS & $\mathrm{NC}$ & NS & $\mathrm{NC}$ & NS \\
\hline \multirow[t]{18}{*}{$\mathrm{GP}$} & Dicamba & BAP & & & & & & & & & & \\
\hline & 2.5 & 0 & 10 & 189 & 10 & 134 & 7 & 122 & 0 & 0 & 0 & 0 \\
\hline & 2.5 & 0.01 & 10 & 186 & 10 & 190 & 10 & 163 & 1 & 5 & 0 & 0 \\
\hline & 2.5 & 0.1 & 10 & 134 & 10 & 90 & 10 & 138 & 7 & 68 & 2 & 5 \\
\hline & 2.5 & 0.5 & 10 & 88 & 10 & 100 & 10 & 62 & 4 & 26 & 1 & 0 \\
\hline & $2,4-\mathrm{D}$ & BAP & & & & & & & & & & \\
\hline & 2.5 & 0 & 10 & 140 & 9 & 140 & 6 & 91 & 4 & 37 & 0 & 0 \\
\hline & 2.5 & 0.01 & 10 & 146 & 10 & 175 & 10 & 216 & 9 & 51 & 0 & 0 \\
\hline & 2.5 & 0.1 & 10 & 213 & 9 & 120 & 7 & 85 & 4 & 17 & 7 & 7 \\
\hline & 2.5 & 0.5 & 10 & 139 & 10 & 127 & 10 & 219 & 6 & 22 & 0 & 0 \\
\hline & Dicamba & Zeatin & & & & & & & & & & \\
\hline & 2.5 & 0.01 & 10 & 204 & 10 & 138 & 6 & 87 & 3 & 44 & 0 & 0 \\
\hline & 2.5 & 0.1 & 9 & 186 & 10 & 120 & 8 & 94 & 1 & 0 & 0 & 0 \\
\hline & 2.5 & 0.5 & 10 & 114 & 10 & 89 & 8 & 139 & 7 & 34 & 0 & 0 \\
\hline & $2,4-\mathrm{D}$ & Zeatin & & & & & & & & & & \\
\hline & 2.5 & 0.01 & 10 & 165 & 10 & 125 & 8 & 90 & 7 & 81 & 0 & 0 \\
\hline & 2.5 & 0.1 & 10 & 87 & 8 & 121 & 6 & 88 & 4 & 41 & 0 & 0 \\
\hline & 2.5 & 0.5 & 10 & 105 & 10 & 141 & 7 & 56 & 6 & 52 & 3 & 2 \\
\hline \multirow[t]{18}{*}{ GL } & Dicamba & BAP & & & & & & & & & & \\
\hline & 2.5 & 0 & 7 & 60 & 9 & 63 & 2 & 15 & 0 & 0 & 0 & 0 \\
\hline & 2.5 & 0.01 & 7 & 54 & 9 & 52 & 0 & 0 & 0 & 0 & 0 & 0 \\
\hline & 2.5 & 0.1 & 9 & 22 & 10 & 31 & 2 & 1 & 0 & 0 & 0 & 0 \\
\hline & 2.5 & 0.5 & 8 & 22 & 4 & 19 & 7 & 43 & 6 & 0 & 0 & 0 \\
\hline & $2,4-\mathrm{D}$ & BAP & & & & & & & & & & \\
\hline & 2.5 & 0 & 1 & 2 & 1 & 4 & 7 & 27 & 0 & 0 & 0 & 0 \\
\hline & 2.5 & 0.01 & 8 & 46 & 7 & 22 & 6 & 24 & 1 & 11 & 1 & 13 \\
\hline & 2.5 & 0.1 & 10 & 18 & 9 & 105 & 7 & 65 & 2 & 24 & 4 & 26 \\
\hline & 2.5 & 0.5 & 6 & 30 & 10 & 57 & 5 & 39 & 5 & 13 & 6 & 6 \\
\hline & Dicamba & Zeatin & & & & & & & & & & \\
\hline & 2.5 & 0.01 & 9 & 36 & 8 & 68 & 10 & 0 & 0 & 0 & 0 & 0 \\
\hline & 2.5 & 0.1 & 7 & 39 & 3 & 12 & 10 & 0 & 0 & 0 & 0 & 0 \\
\hline & 2.5 & 0.5 & 7 & 7 & 2 & 5 & 10 & 0 & 0 & 0 & 0 & 0 \\
\hline & $2,4-\mathrm{D}$ & Zeatin & & & & & & & & & & \\
\hline & 2.5 & 0.01 & 3 & 19 & 5 & 42 & 5 & 28 & 0 & 0 & 0 & 0 \\
\hline & 2.5 & 0.1 & 5 & 36 & 5 & 25 & 10 & 0 & 0 & 0 & 0 & 0 \\
\hline & 2.5 & 0.5 & 2 & 6 & 2 & 4 & 8 & 4 & 0 & 0 & 0 & 0 \\
\hline
\end{tabular}

The calli were induced from half-immature embryos (IEs) and maintained on callus-induction medium and then regenerated on FHG. The induction and regeneration times are 22 days after plating half-IEs and 25 days after plating calli for the 3rd transfer, 47 and 20 days for the 4 th transfer, 56 and 25 days for the 5 th transfer, 83 and 25 days for the 7 th transfer, and 115 and 25 days for the 9th transfer, respectively.

*1 $\mathrm{NC}$ is the number of green calli from 10 initial calli.

$* 2 \mathrm{NS}$ is the number of green shoots from 10 initial calli.

formable cultivar, GP, and a recalcitrant commercial cultivar, GL. This study was necessitated by the fact that, utilizing the published medium [1] $(2.5 \mathrm{mg} / \mathrm{L}$ dicamba/no cytokinin) for callus induction and maintenance in transformation attempts of GL, large numbers of transformed callus lines were obtained but they were either nonregenerable or yielded only albino plants (unpublished data).

Medium composition and phytohormone types and levels were found to be important factors in the in vitro responses of both cultivars examined in the present study. Certain generalizations can be made regarding the effects of different cytokinins on the properties of proliferated callus. Although zeatincontaining medium appeared to support faster growth rates for both cultivars (Fig. 2), its use with either auxin led to lower quality callus than BAP plus either auxin by supporting vigorous growth of soft, lightcolored callus (Table 1). The detrimental effects of zeatin are also reflected in the comparisons of the 


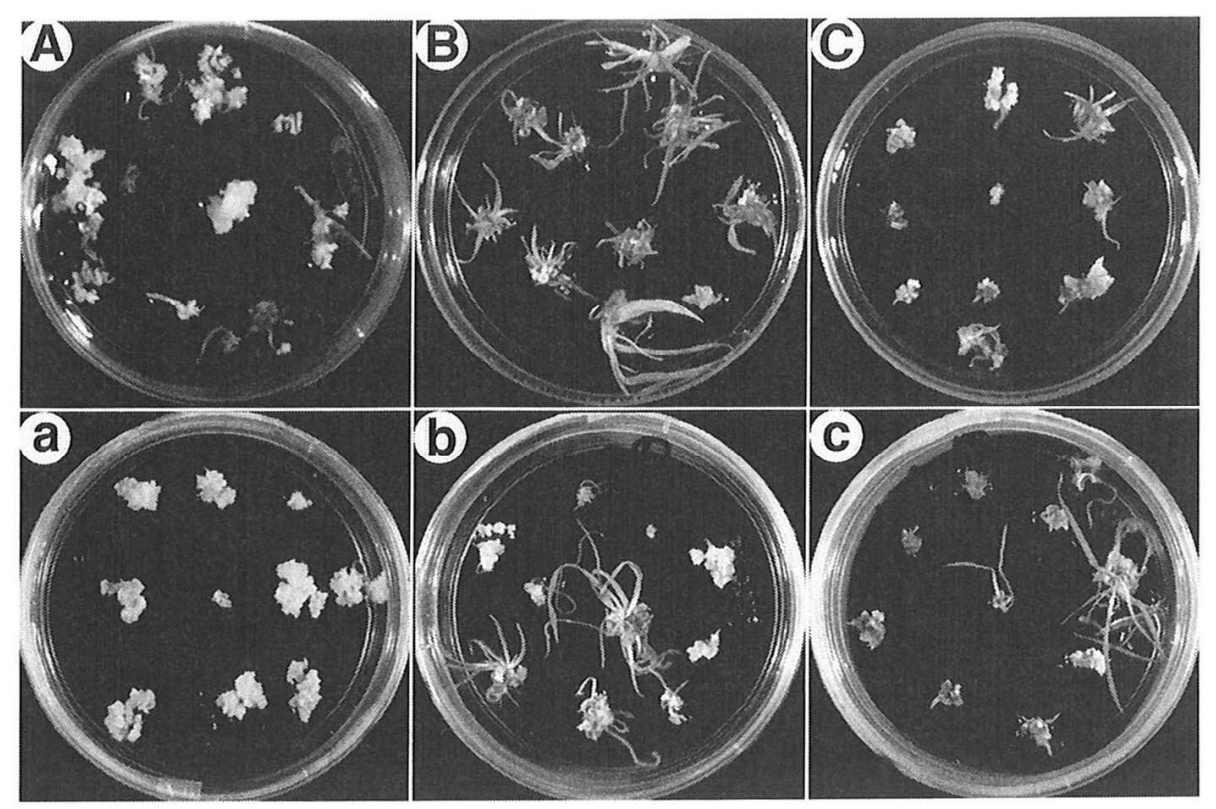

Fig. 3 Generation of green shoots from callus of two barley cultivars, Golden Promise $(\mathrm{A}-\mathrm{C})$ and Galena $(\mathrm{a}-\mathrm{c})$, grown on three different callusinduction media. The hormone combinations of the different media are as follows: A and a, $2.5 \mathrm{mg} / \mathrm{L}$ of $2,4-\mathrm{D}$ alone; $\mathrm{B}$ and $\mathrm{b}, 2.5 \mathrm{mg} / \mathrm{L}$ of 2,4-D plus $0.01 \mathrm{mg} / \mathrm{L}$ of BAP; $\mathrm{C}$ and c, $2.5 \mathrm{mg} / \mathrm{L}$ of $2,4-\mathrm{D}$ plus $0.1 \mathrm{mg} / \mathrm{L}$ of BAP. Photographs were taken 3 weeks after transfer of 3 -month old calli onto regeneration medium.

regenerative potential of calli from both cultivars grown on zeatin- versus $\mathrm{BAP}$-containing medium. Use of zeatin at levels from 0.01 to $0.5 \mathrm{mg} / \mathrm{L}$ led to the production of calli that were not as regenerable as calli grown on BAP-containing medium (Table 2). This is in contrast to other studies $[6,7]$ which showed that, in combination with IAA, use of zeatin or zeatin riboside improved regenerability of callus of $H$. vulgare, $H$. spontaneum and $H$. bulbosum. Our inability to observe a positive effect of zeatin on the in vitro response of $\mathrm{GP}$ and $\mathrm{GL}$ might be due to differences in the cultivars or auxins in the two studies, or to other modifications in the culturing procedures in the two studies.

In contrast to zeatin the addition of BAP to 2,4-Dcontaining medium decreased the growth of the soft, friable callus and increased the frequency of occurrence of shiny, compact and slightly brown-colored callus found to be more regenerable (Table 1; Fig. $\mathbf{1 A} / \mathbf{B}, \mathbf{a} / \mathbf{b})$. Rengel and Jelaska [16] also found that the use of BAP and 2,4-D in CIM significantly enhanced embryogenic callus formation in barley; however, they found that these changes also led to necrosis at later stages.

We tested the regenerability of callus cultures at times comparable to those encountered during the selection process used for transformation. In many cases calli grown on media containing low concentrations of $\operatorname{BAP}(0.01 / 0.1 \mathrm{mg} / \mathrm{L})$ plus $2,4-\mathrm{D}$ yielded the largest numbers of regenerated shoots for both GP and GL (Table 2). 2,4-D is the most commonly used auxin for embryogenic callus formation in cereal crops; however, the addition of cytokinin to 2,4-D can result in significant differences in response depending on the plant species and cultivar (for review, Bhaskaran and Smith; [23]). Recently, multiple shoots were generated from in vitro-cultured meristems of maize [24] and oat [25] proliferated on BAP and 2,4-D. The effect of BAP on shoot regeneration observed in this study is also consistent with previous observations on seed-derived callus of Kentucky bluegrass [26] and creeping bentgrass [27] where higher frequencies of shoot regeneration were achieved when either dicamba or 2,4-D and BAP were substituted for auxin alone.

Negative effects of the length of culture time on regenerative potential are also seen in this study, e.g. calli of GP and GL began to lose the ability to yield shoots after the fifth and fourth transfer, respectively. These negative effects are more dramatic with GL than GP on all media tested, except for those with 2,4-D plus BAP. As has been observed previously [28], there also appeared to be an effect of length of culture time on albinism. The effect on GL appeared more marked as evidenced by the lower numbers of green calli in the GL cultures relative to GP at the last two time points for most media (Table 2). In addition, although some albino plants were produced from 
both GP and GL at the later transfer times, the albinism in GL was more marked (unpublished data). In conclusion, based on the data presented in this study, 2,4-D in combination with BAP at concentrations between $0.01-0.1 \mathrm{mg} / \mathrm{L}$ is optimal for both GP and GL in terms of prolonging regenerability and producing the highest NC and NS. This improvement in callus quality characteristics should increase the probability of transformation success with GL and the general principles discovered in these studies should be useful for other recalcitrant varieties of barley and perhaps other monocot species.

\section{Acknowledgments}

M.-J. Cho and W. Jiang were supported by a grant from the Coors Brewing Company; M.-J. Cho also from the USDA NRI (\#93-37500-9586). P. G. Lemaux was supported by the USDA Cooperative Extension Service through the University of California. The authors thank B. Treat (Coors Brewing Company, Golden, CO) for GL seeds and P. Bregitzer (USDA-ARS Small Grains Germplasm Center, Aberdeen, ID) for GP seeds.

\section{References}

[1] Wan, Y., Lemaux, P. G., 1994. Plant Physiol., 104 : 37-48.

[2] Dmitrieva, N. N., 1985. In "Plant Cell Culture, Biology Series” (ed. by Butenko, R. G.), p. 35-50, MIR Publishers, Moscow.

[3] Tisserat, B., 1985. In "Plant Cell Culture: A Practical Approach, Practical Approach Series" (ed. by Dixon, A.), p. 79-105, IRL Press, Oxford, Washington, DC.

[4] Hagio, T., Hirabayashi, T., Machii, H., Tomotsune, H., 1995. Plant Cell Rep., 14: 329-334.

[5] Fletcher, R.A., 1969. Planta, 89: 1-8.

[6] Lürz, R., Lörz, H., 1987. Theor. Appl. Genet., 75 : 16-25.

[7] Breimann, A., 1985. Plant Cell Rep., 4: 161-163.

[8] Lemaux, P.G., Cho, M.-J., Louwerse, J., Wil- liams, R., Wan, Y., 1996. Bio-Rad US/EG Bulletin, 2007: 1-6.

[9] Koprek, T., Haensch, R, Nerlich, A., Mendel, R. R., Schulze, J., 1996. Plant Sci., 119: 79-91.

[10] Murashige, T., Skoog, F., 1962. Physiol. Plant., 15: $473-497$.

[11] Hunter, C. P., 1988. Ph.D. thesis. Wye College, Univ. of London, Ashford, Kent.

[12] Dale, P. J., Dambrogio, E., 1979. Z. Pflanzenphysiol., 94: 65-77.

[13] Hanzel, J. J., Miller, J. P., Brinkmann, M. A., Fendos, E., 1985. Crop Sci., 25: 27-31.

[14] Bregitzer, P., 1992. Crop Sci., 32: 1108-1112.

[15] Dahleen, L. S., 1996. Plant Cell Tiss. Org. Cult., 43: 267-269.

[16] Rengel, Z., Jelaska, S., 1986. J. Plant Physiol., 124 : 385-392.

[17] Ziauddin, A., Kasha, K. J., 1990. Euphytica, 48: 171-176.

[18] Bregitzer, P., Campbell, R. D., Wu, Y., 1995. Plant Cell Tiss. Org. Cult., 43: 229-235.

[19] Hang, A., Bregitzer, P., 1993. J. Hered. 84: 105108.

[20] Mohanty, B. D., Ghosh, P. D., 1988. J. Bot., 61: 551-555.

[21] Baillie, A. M. R., Rossnagel, B. G., Kartha, K. K., 1993. Can. J. Plant Sci., 73: 171-174.

[22] Goldenstein, C. S., Kronstadt, W. E., 1986. Theor. Appl. Genet., 71: 631-636.

[23] Bhaskaran, S., Smith, R. H., 1990. Crop Sci., 30: 1328-1336.

[24] Zhong, H., Srinivasan, C., Sticklen, M.B., 1992. Planta, 187: 483-489.

[25] Zhang, S., Zhong, H., Sticklen, M. B., 1996. J. Plant Physiol., 148: 667-671.

[26] Griffin, J. D., Dibble, M. S., 1995. Plant Cell Rep., 14: $721-724$

[27] Zhong, H., Srinivasan, C., Sticklen, M. B., 1991. Plant Cell Rep., 10: 453-456.

[28] Kott, L. S., Kasha, K. J., 1984. Can. J. Bot., 62: 1245-1249. 